\title{
XXXI.
}

\section{Zur Pathologie der postfebrilen Dementia}

\section{nebst Bemerkungen über die Nervenfasern der \\ Grosshirnrinde.}

Von

\section{Prof. H. Emminghaus}

in Dorpat.

(Hierza Taf. X. and XI.)

Durch die 'umfassende Arbeit von E. Kraepelin „Veber den Einfluss acuter Krankheiten auf die Entstehung von Geisteskrankheiten ${ }^{\text {(c*) }}$ ist die Lehre vom postfebrilen Irresein in jhrem klinischen Theile vorläufig zum Abschluss gelangt. Casuistische Mittheilungen, welche nur die Pathogenese, die Erscheinungen und Formen sowie den Verlauf dieser ziemlich häufigen Psychosen betreffen, dürften daher gegenwärtig wohl überflüssig sein. Anders verhält es sich mit Beobachtungen, die auch den pathologiseh-anatomischen Antheil des Gegenstandes betreffen. Denn dieser befindet sich noch immer in dem unentwickelten Zustande, in welchem ihn schon Kraepelin antraf. Es fehlt noch gänzlich an genauen mikroskopischen Untersuchungen der Hirnsubstanz in solchen Fällen, die während des Verlaufes der postfebrilen Psychose selbst tödtlich abgelanfen sind. Auf diesem Gebiete des Wissens ist die Pathologie des Rückenmarks, die ebenfalls von postfebrilen Erkrankungen zu berichten hat, der Pathologie der Hirnrinde schon lange um einen wesentlichen Schritt voraus. Denn schon im Jahre 1872 konnte Westphal**) in zwei Fällen den

*) Kraepelin, Dieses Archir Bd. XI. und XII.

*) Westphal, Berliner klin. Wochenschr. 1872. No. 47.

Archiv f. Psychiatrie. XVIT. 3. Hrft. 
Nachweis liefern, dass schwerer, mit Blasenlähmung verbundenen Paraplegie nach Pocken eine mikroskopisch diagnosticirbare disseminirte Myelitis entsprach.

Die folgende Mittheilung betrifft nun einen Fall, der allen Anforderungen entspricht, welche heute an die pathologische Anatomie der postfebrilen Geistesstörungen gestellt werden müssen: die acute Allgemeinkrankheit war vollständig abgelaufen, die Psychose aber hatte erst ein paar Monate bestanden, das Centralnervensystem wurde nicht willkürlich, sondern topographisch und mikroskopisch genau mit den verbesserten Methoden untersucht, über welche die Neuzeit verfügt.

Zwar sind die Veränderungen der Hirnrinde, welche sich fanden, nicht sehr erheblich. Aber gerade dieser Umstand gewinnt an Bedeutung, wenn man bedenkt, dass zahlreiche Fälle dieser Art von Psychosen mit Heilung endigen. Demnach wäre es wohl denkbar, dass in diesem Falle der mikroskopischen Untersuchung Texturveränderungen sich erschlossen, welche Ausgleichung hätten finden können, wenn das Leben erhaiten geblieben wäre.

Der Bericht über den mikroskopischen Befund enthält zugleich einige, durch Abbildungen erläuterte Bemerkungen über das Nervenfaserngefüge der Hirnrinde, welche die Angaben von Kölliker*), Gerlach ${ }^{* * *}$, Exner**), Tuczek ${ }^{*}$ ) über diesen Gegenstand noch etwas vervollständigen.

Hugo 0., 19 Jahre alt, Student der Mathematik der St. Petersburger Universität, früher immer gesund, frei von erblicher Belastung (der Vater soll nur etwas reizbar sein), von rubigem Charakter, sehr energisch und sehr gut begabt, von sehr solidem Lebenswandel, erkrankte im Februar 1884 in St. Petersburg an Febris recurrens von schwerem, langwierigem Verlaufe. Die Reconvalescenz, welehe er auf dem Lande bei seinen Eltern durchmachte, ging sehr langsam yon statten. Während derselben änsserte er Sorgen um seine Zukunft, z. B. dass er das durch die Krankheit Versäumte nicht nachholen lönne, dass ihm die Mittel zur Fortsetzang seiner Studien fehlten. Letzteres war vollkommẹn unbegründet, da der Vater sich in guten Verhältnissen befand. Bald trat nun bei dem Kranken eine im Vergleich zu seinem früheren Naturell ganz ungewöhnliche und anhaltende Unruhe hervor: er wurde unstät, trieb sich ausser dem Hause herum, im Hause aber kramte und wühlte er in

*) Kölliker, Mikroskopisehe Anatomie 1850. Bd. II. S. 477.

***) Gerlach, Centralbl. f. d. med. W. 1872. No. 18.

**) Exner, Sitzungsber. der Wiener Academ. Mathem. naturw. Classe. Bd. LXXXIII. Abth. III., 1881, Heft I. S. 151.

†) Tuczek, Mendel's Centralbl. 1882. S. 315. - Beiträge f. path. Anat. und Path. d. Dem. paralyt. Berlin 1884. 
allen Zimmern und Schränken, wo er eine chaotische Unordnung anrichtete, die zu repariren ihm gar nicht einfiel. In das Haus eines nahe wohnenden

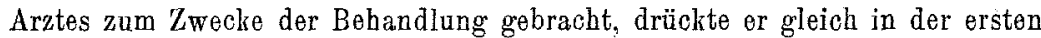
Nacht die Fensterseheiben ein, entwich und kehrte in das Elternhaus zurück. Auf Befragen motivirte er seine Entweichung und die Rückkebr damit, dass er habe ein Bedürfniss befriedigen wollen, die Thür aber verschlossen gewesen sei. In dieser Zeit war er einmal, als er sich draussen herumtrieb, mit Bauern in Conflict gerathen und von diesen geprügelt worden. Man bemerlte, dass or "mit verändertem Wesen ron diesem Spaziergange zurückkehrte", er war schen, verworren, sprach nur noch einzelne Worte, aus welchen, soweit si überhaupt verständlich waren, hervorging, dass er hierhin und dorthin über Land zu fahren wünschte. Anstalten, diese Wünsche zu realisiren, traf er nicht. Am 11. Juni 1884 wurde der Kranke der psychiatrischen Klinik zugeführt.

Die Aufnahme eines regelrechten Status praesens war bei dem Eintritte des Kranken in die Anstalt nicht möglich. Denn derselbe verhielt sich keinen Augenblick ruhig, rannte fortwährend herum und floh sobald man sich ihm näherte. Wurde er angefasst, so wand und drehte er sich, kauerte sich auf dem Fussboden zusammen, sodass von einer ordentlichen Untersuchung gar nicht die Rede sein konnte. Begütigende Worte hatten nicht den geringsten Erfolg. Auf Fragen, deren eine grosse Anzahl an den Kranken gestellt wurden, erhielt man gar keine Antwort, man sah keine Veränderung des eigenthümlichen, bald zu beschreibenden Gesichtsausdrucks, obwohl diese Fragen Familie. Vorleben, Studien, die abgelaufene schwere Krankheit etc. betrafen.

So blieb wegen der masslosen Unruhe und Scheu des Kr. nichts übrig, als die Aufnahme des Status praesens noch zu verschieben. Was man theils auf den ersten Blick, theils nach der unter heftigem Widerstreben bewirkten Entkleidung des Kranken vor dem Aufnahmebade feststellen konnte, ist Folgendes: Mittlere Statur, graciler Knochenbau, bedentende Abmagerung, schwache Muskulatur; welke, bräunlich pigmentirte Haut, zablreiche Furunkel und furunkulöse Geschwüre in derselben. Blässe der Schleimhäute. Haltung gebückt, (marantische Kyphose) bei stark vorgestrecktem Kopfe; untere Körperhälfte und Bekleidungsstücke mit Koth befleckt, mit Urin benetzt; Harnträufeln begleitet die wilden Widerstandsbewegungen, die Patient jeder Manipulation entgegensetzt. Bei dieser Gelegenheit sowie bei den Fluchtversucher erweisen sich die Bewegungen von Stamm und Extremitäten als ganz symmetrisch, sehr flink, aber plump und kraftlos.

Eigenthümlich ist die, wie erwähnt, bei allen Fragen, bei allen Fluchtversuchen und Widerstandsactionen und auch, wenn der Kranke sich selbst überlassen wird, in starrer Unveränderlichkeit verharrende Physiognomie. Die Augen, welche mattglänzend - mit beiderseits gleichen ad maximum erweiterten, aber prompt auf Lichtreiz reagirenden Pupillen - tief halonirt in den Höhlen liegen, sind mittelweit geöffnet, ihre Axen parallel, der Blick in die Ferne gerichtet, die Stirn in tiefe Horizontalfalten gezogen, die senkrechten Stirnfalten schwach; tiefe doppelte Nasolabialfalten; Mund leicht geöffnet, die 
Winkel desselben nach oben gezogen. Indem diese Innervationen der Gesichtsmuskeln beiderseits ganz gleich sind und, wie gesagt, ganz unveränderlich bleiben, gewinnt man den eigenartigen Eindruck von ernst erstaunter Miene in der oberen, von heiterem Zuge in der unteren Antlitzhälfte.

Im Verlaufe der nächsten Tage gelang es nach und nach diesen dürftigen Status praesens etwas zu vervollständigen. Die Empfindlichkeit für Schmerzeindrücke ist abgestumpft: ein nnerwartetes Knøifen, rücklings ausgeführt, kat keine Reaction zur Folge; in den Furunkelgeschwüren, von welchen Patient mit Fingern und Zähnen die Verbärde abreisst, wüblt er mit den Nägeln herum, lässt anch damit nicht nach, als dieselben bluten.

Bei dem anhaltenden Herumlaufen des Kranken, bei seinem Flüchten vor den Menschen - vor anderen Kranken, Wärtern, Aerzten ohne Unterschied - adaptirt er seine, wie schon erwähnt, sebr flinken, aber plumpen Bewegungen den Gesichtseindrücken; er kriecht in Ecken, steigt auf Betten und Bänke, rennt gleich aus dem Isolirzimmer, sowie die Thür geöffnet wird. Das Sichwinden, Hinkauern beim Versuche des Festhaltens danern fort. Einmal rennt er auf ein Fenster zu und rüttelt an dessen (innerem) Gitter. In einem ruhigen Augenblick in das Aufenthaltszimmer gebracht, nimmt er nicht die geringste Notiz von den anderen Kranken und als ihm, während er auf der Bank vor dem Tische sitzt, ein Buch mit Abbildungen vorgelegt wird, stiert er (ohne dass sich seine Miene dabei verändert) lange Zeit die aufgeschlagenen Seiten an; es fällt ihm nicht ein umzuwenden, geschweige denn zu blättern. Obwohl sich ein Nachtgeschirr in seinem Zimmer befindet, deponirt er Fäces und Urin auf die Diele, ohne sich indessen damit zu schaffen zu machen. Das Führen und Placiren auf den Abort veranlasst ihn nicht zur Entleerung. $\mathrm{Zu}$ den üblichen Mahlzeitsstunden hingestelltes Essen lässt er öfter lange Zeit unbeachtet, verzehrt es nur gelegentlich, dann aber hastig bis auf den letzten Rest. Ist er isolirt und entsteht Geräusch auf dem Corridor, so rennt er an die Thür des Zimmers, um herauszustürzen, sowie sich dieselbe öffnet. Auf Fragen antwortet er, wie bei der Aufnahme, meist gar nicht, hier und da mit einem unverständlichen Schwall von Lauten, die er nur in Flüsterstimme hervorstösst. Spontan giebt er keinen Laut von sich. Die erste Nacht*) ist er viel wach und unruhig, rennt auch wie am Tage sofort durch die geöffnete Thür.

Der anfgefangene Urin ist ohne Eiweiss und Zucker, reich an Phosphaten. An der linken Lungenspitze constatirt man (wegen der Unruhe des Kranken mit Mühe) eine erhebliche Dämpfung, am Herzen Spaltung der 2. Töne an der Basis. Auf die Kleinheit und Beschlennigung des Pulses, welche in der Krankengeschichte notirt ist, fällt wenig Gewicht, da diese Untersuchung unter lebhaftem Widerstande des Kranken stattfand. Eine Feststellung des Verhaltens der Haut- und Sehnenreflexe, des Zustandes der Abdominalorgane gelang unter den gegebenen Umständen nur unvollkommen, gröbere Anomalien waren aber sicher ausgeschlossen. Temperaturmessungen warén ebenfalls

*) Die Nächte in der Mitte des Juni sind hier zu Lande fast taghell. 
ganz unmöglich, indessen gab die manuelle Untersucbung sicheren Aufschluss darüber, dass kein Fieber vorhanden war.

Die anamnestischen Angaben und der vor der Hand nur in den Hauptsachen ermittelte Status praesens schienen mir doch hinreichend, um die Diagnose Dementia postfebrilis acuta zu sichern.

Dass die geistige Störung postfebril war und sich noch im acuten Stadium befand, unterlag ja keinem Zweifel. Festgestellt war: vollkommenes geistiges Normalverhalten, sogar sehr gute Begabung (erfolgreiches Studium der Mathematik), energischer Charakter, ganz regelmässige Lebensführung bis zum Beginn der fieberhaften Krankheit. In der Reconvalescenz von letzterer war die psychische Störung aufgetreten und sie hatte bei der Aufnahme erst zwei Monate bestanden; chronisch war sie also noch nicht.

Anfangs war eine bypochondrisch-melancholische Verstimmung dagewesen: sebr bald aber waren Unruhe, Herumtreiben ausser dem Hause, Wühlen und Kramen in den Sachen gefolgt, Erscheinungen, wie man sie bei anderen Formen der Dementia ganz besonders zu Beginn des senilen Blödsinns beobachtet und als Zeichen der Erinnerungs- und Gedächtnissschwäche, der Ideenflucht und des motorischen Dranges, also verminderter geistiger Hemmung ansieht. Dazu war als ein weiteres Zeichen der Unruhe und des impulsiven Wesens gekommen die Entweichung aus dem Hause des Arztes gleich in der ersten Nacht, die sich an dieselbe anschliessende Rückkehr in das Elternhaus. Die eigenthümliche Motivirung, welche der Kranke diesen Acten gab, weist auf schon damals vorhandene Schwäche des Denkens hin; denn sie schliesst in sich einen bedeutenden Irrthum hinsichtlich der Fragestellung. Das Verschlossensein der Thür konnte wohl bei auftretendem Bedürfniss das Eindrücken der Fensterscheiben und das Heraussteigen zum Fenster rechtfertigen, nicht aber die Flucht nach Hause.

Nach einer Misshandlung, die der Kranke bei seinem Herumvagiren ansser dem Hanse sich zugezogen hat, ist und bleibt er ganz verwirrt, spricht nur noch abgebrochene Worte, die wiederum lediglich den Drang nach Ortsveränderung andeuten.

Völlig vernachlässigt, mit Dejectionen beschmutzt und mit verwahrlosten Hautgeschwüren behaftet, wird er der Klinik zugeführt. Seine sinnlichen, ästhetischen und ästhetisch-moralischen Gefühle erweisen sich somit als völlig abgestumpft. Mit dieser für die Geistesschwäche so charakteristischen Gefühlsstumpfheit verbinden sich Defecte des sinnlichen Urtheils: Nichterkennen des Essgeschirrs nebst Inhalt auf den ersten Blick (unregelmässiges, gelegentliches Anffinden 
der Speisen), Entleerung der Dejectionen neben das Nachtgeschirr, Nichterkennen der Abortseinrichtung, wiederum Symptome, die allen Formen der Dementia eigenthümlich sind. Gleichwerthig mit diesen Ansfallserscheinungen ist für einen hochgebilden Menschen, wie der Kranke war, das Verkennen der Verbände der Hautgeschwüre u. s. w., das Anstieren der Bilder und der Schrift eines vorgelegten Buches ohne irgend welches Zeichen von Verständniss, von Interesse. Dass der Kranke die umgebenden Nenschen ignorirte, schien damit im Einklang zu stehen.

Es war also bei nachweisbar erhaltenem Sehvermögen nicht einmal die so elementare Neugierde vorhanden, welche durch Bilder und den Anblick von unbekannten Menschen hervorgebracht wird. Die im Zimmer befindlichen Kranken erregten offenbar deshalb nicht Angst und Schrecken bei dem Patienten, weil sie ruhig an ihrem Orte verharrten und ihm nicht nahe kamen. Es handelte sich demnach um einen gewissen Grad von Seelenblindheit, um einen Zustand, in dem eine geistige Verarbeitung sehr vieler optischer Bilder, die Richtung der Aufmerksamkeit auf zahlreiche Gesichtseindrücke nicht stattfand und nur eine kleinere Gruppe von optischen Wahrnehmungen (Annäherung menschlicher Gestalten) psychische Wirkungen hervorbrachten. Gleichbedeutend war der bei ebenfalls nachweisbarer Hörfähigkeit bestehende Mangel des Sprachveständnisses, die sensorische Aphasie oder Worttaubheit, welche zunächst erschlossen werden musste aus dem Mangel jeder physiognomischen Reaction auf alle, selbst sehr nahe gehende und gemüthsbewegende Fragen, aus der gänzlichen Erfolglosigkeit begütigender Worte bei dem wilden Widerstande des Kranken gegen Berührung. Das Ausbleiben der Antworten stimmte damit überein. Das Lossreissen der Verbände aber bewies, dass die so einfache Idee: „Nutzen und Schaden der eigenen Person“ ausgefallen war. Es kam hinzu die Abstumpfung der Schmerzempfindlichkeit, welche durch den Ausfall der Reaction auf hier verbotenus unversehens beigebrachte Insulte der Hautnerven und namentlich durch das Wühlen des Kranken in seinen Geschwüren mit den Nägeln erwiesen war. Diese Erscheinungen machten im Hinblick auf die neueren experimentellen und klinischen Erfahrungen über die Leistungen der Hirnrinde zum Mindesten tiefe functionelle Störung, wo nicht organische Erkrankung eines sehr grossen Abschnittes der Corticalsubstanz wahrscheinlich. Sah man doch Erscheinungen, welche auf Läsionen der Hinterhauptslappen, der Schläfenlappen, der Scheitellappen, der Centralwindungen und der Ursprungsgebiete der Stirnwindungen hinwiesen! 
Die wenigen positiven psychischen Lebensäusserungen, welche sich zeigten, liessen ebenfalls nur den Schluss auf Dementia zu. Im weiteren Sinne gehört hierher schon der Gesichtsansdruck des Kranken, welcher eine disharmonische Mischung von Heiterkeit in der unteren Hälfte, von Ernst und Erstaunen in der oberen Hälfte des Gesichtes darbietet. Es lässt sich derselbe wegen der leichten Oeffnung des Mundes mit hochgestellten Winkeln bei mittelweit offenen Augen, in die Ferne gerichtetem Blicke und den tiefen Horizontalfalten der Stirn nur vergleichen mit der Physiognomie, welche der naive Gesunde im Augenblicke der Ueberraschung höchsten Grades zeigt, wenn ihm Eindrücke auf die Sinne unverständlich sind und damit sein Denken momentan stille steht. Indem dieser Gesichtsausdruck bei dem Kranken aber völlig unveränderlich ist, trotz aller psychischen Reize, selbst bei dem auf Furcht und Angst hindeutenden Flüchten vor Menschen sich nicht umwandelt, illustrirt er ohne Weiteres den Zustand geistiger Schwäche*). Denn dergleichen zerrüttete und starre Physiognomien trifft man fast ausschliesslich beim Blödsinn, nicht selten gerade bei der acuten Form desselben ${ }^{*}$ ).

Der zweck- und ziellose, von Anbeginn der geistigen Störung beobachtete und noch fortbestehende Drang zur anhaltenden Ortsveränderung ist, wie schon hervorgehoben wurde, ebenfalls charakteristisch für den Blödsinn. Derselbe bedarf kaum der Erläuterung, da er ja ständige Eigenschaft ganzer Gruppen von Idioten und mit tiefer Dementia behafteten Geisteskranken ist, bei denen nur der Begriff „was anderes“ und der Impuls, denselben anschanend zu verwirklichen als dumpfe Vorstellungen noch vorhanden sind. Einmal nur wurde constatirt, dass der Kranke an einem Hinderniss, das seinem wüsten Ortsveränderungsdrang entgegen stand, sich vergriff es war das Rütteln an dem Fenstergitter. Ein Erkenntniss des Hindernisses hatte also stattgefunden, aber wer wüsste denn nicht, dass

*) Denkt man sich auf Tafel 98 von Morison's Physiognomik der Geisteskranken den Mund des Portraits der senil-dementen Frai nur ein wenig geöffnet, so hat mandiePhysiognomie des Kranken, woza, was Falten und gealtertes Aussehen anlangt, sein tiefer Marasmus das seinige beiträgt.

**) Veränderungen des Gesichtsausdrucks beobachtete schon Westphal (Dieses Archiv Bd. III. S. 376 ff.) bei cerebrospinaler Erkrankung nach Variola. In der ersten Beobachtung W.'s scheint die Veränderung der Physiognomie der von mir beschriebenen Entstellung ähnlich gewesen zu sein. Auch in diesem Falle war psychische Störung, freilich von sehr geringem Grade, nachweisbar. 
derartige Leistungen oft genug bei tief Blödsinnigen vorkommen? Etwas höheren geistigen Werth beansprucht dagegen das Flüchten des Kranken vor ihm sich nähernden Menschen und sein Zusammenkauern, Sichwinden mit Anpassung an die Bewegungen des Betreffenden, wenn einer ihn festzuhalten versucht. Furcht und Angst, Antecipation von Unlustgefühlen der nächsten Zukunft, also sehr einfache Schlüsse mussten hierbei stattfinden. Der bei solchen Gelegenheiten eintretende Abgang von Urin schien zugleich die ängstliche psychische Emotion zu erweisen. Aber solche psychische Leistungen sind doch nichts Ungewöhnliches bei blödsinnigen Individuen; bewahren doch tiefstehende Idioten, Vollcretinen, Tiefdemente genau und leicht reproducirbar die Vorstellungen von sinnlichen Wehgefühlen (wie Lustgefühlen) und deren Ursachen, belebten wie leblosen, oft scharf im Gedächtniss! In charakteristischer Weise findet bei ihnen nur allzuleicht eine vage, daher ganz falsche Verallgemeinerung dieser Vorstellungen durch confuse Analogieschlüsse statt. Und so war bei unserem Kranken ganz offenbar die in der Geistesstörung erlebte Prügelkatastrophe mit den Bauern, die sich seinem Gedächtniss eingeprägt hatte, Veranlassung geworden, dass Furcht, Angst vor dem Nahetreten von Menschen schlechthin und überhaupt jeweilig in ihm rege wurde. Unzweideutig geht die Richtigkeit dieser Annahme daraus hervor, dass sein menschenscheues Benehmen. sich gar nicht änderte, nachdem er wiederholt zum Bade entkleidet und nach demselben angekleidet, wiederholt auf den Abort geführt worden war, er dabei aber keinen Insult erfahren hatte. (Die unversehens zum Zwecke der Sensibiltätsprüfung ihm beigebrachten Reizungen von Hautnerven waren ja für sein Bewusstsein verlorene Eindrücke!) Jedenfalls also haftete bei ihm - wenn er sie überhaupt gehabt hatte - die Erkenntniss nicht, dass wir alle, Aerzte und Wärter, nicht sinnliche Qualen ihm erregt hatten (wie jene Bauern, von denen er geprügelt worden war). Es fehlte also gänzlich die Fähigkeit, Abstractionen aus dem Material der wenigen, dem Kranken noch zum Bewusstsein kommenden Sinneseindrücke und deren etwaigen Erinnerungen zu ziehen und ein solches auf den Begriffen der Identität und Negation beruhendes Wissen von Neuem zu erwerben. Und die Thatsache wog gewiss am allerschwersten für die Annahme bestehender Dementia! Betrafen doch diese Defecte gerade die einzigen abstracten Vorstellungen, welche sich bei dem Kranken noch als bestehend nachweisen liessen.

Endlich waren die Bewegungen der Extremitäten und des Stammes zwar sehr flink, aber plump und kraftlos, die Haltung des Rumpfes gebückt. Mochten diese Erscheinungen leichter Coordinations- 
störung und Parese auch zum Theil in der sichtbaren Abmagerung und Schwäche begründet sein, der Verdacht, dass sie auch von einer centralen Erkrankung, und zwar speciell einer solchen der Centralwindungen, des Lobus parietalis abhängig sein konnten, war nicht von der Hand zu weisen. (Gründe für die Annahme einer spinalen Affection lagen ja im Leben nicht vor.)

Verordnet wurden ausser der Localbehandlung der Hautgeschwüre, welche sich bei dem unruhigen Zustande des Kranken auf Waschungen mit Sublimatlösung beschränken mussten, tägliche warme Bäder, Wein, Erziehang zur regelmässigen Nahrungsanfnahme, zur regelmässigen Defäcation, womöglich Bettliegen. Der Verlauf der Krankheit gestaltete sich folgendermassen:

In den nächsten Tagen wurde einige Beruhigung und selteneres Verunreinigen der Diele mit Dejectionen, nach und nach Gewöhnung an Entleerungen auf dem Abort, bald auch regelmässige Nahrungsaufnahme constatirt. In den Nächten ruhiger Schlaf; aber der Kranke war nicht zum Verweileü im Bette zu bringen. Der Versuch das Körpergewicht zu bestimmen, brachte eine tarbulente Scene hervor: Patient verharrte nicht einen Augenblick rubig auf der Wage, so dass von der Gewichtsbestimmung Abstand genommen werden musste.

Jeden Tag wiederholte sich bei der ärztlichen Visite dieselbe Scene, dass der Kranke vor uns floh oder, wenn er isolirt war, im Momente, da sich die Thür öffnete, zwischen uns hindurch kroch, um das Weite za suchen. Offenbar weckte ein herankommender Trupp von Menschen bei ihm alle Mal die Erinnerung an die in der Krankheit erlebte Prügelkatastrophe; beim gelegeitlichen Erscheinen des Assistenzarztes alle in blieb die Flucht schliesslich ganz aus. Bei solchen Gelegenbeiten fuhr er dann gerne auf die goldene Uhrkette des Arztes zu und fasste sie mit der Hand fest (wiederum eine ächt blödsinnige Erscheinung) und einmal flüsterte er die Worte: „bitte, bitte“, als ihm die Uhrkette entzogen wurde. Anderweitige Sprachäusserungen wurden auch weiterhin nicht bemerkt.

Inzwischen entwickelten sich massenhaft neue Furnnkel an den versohiedensten Stellen der Haut, mit diesen Oedem an den unteren Extremitäten, rapide zunehmende Abmagerung (bei regelmässiger Nahrungsaufnahme). Die Unruhe nahm nicht ab. Eine erneute mit Mühe durchgesetzte Untersuchung der Lunge ergab das Fortbestehen der Dämpfung des Percussionsschalles über dem linken Schlïsselbein, auch schwache Dämpfung unterhalb desselben. Ueber das Verhalten der Athmongsgeräusche konnte Zuverlässiges nicht festgestellt werden, weil der Kranke zu unruhig war.

Am Morgen des 9. Juli plötzlicher Collaps mit Coma, Cyanose, verlangsamte unregelmässige Respiration (16 in zwei Minuten). Faradische Reaction des Phrericus sehr schwach, zugleich herabgesetzte und träge faradische Erregbarkeit.der Intercostal- und Bauchmuskeln. Temperatur 30,6 C., Puls sehr 
klein, 75. Heratöne sehr leise, ohne Geräusche, ohne Spaltung. Sehnenreflexe normal, Hautreflexe träge und schwach. Stimulantien (Weinklystiere, subcutane Injection von 0l. camphorat.) vermögen den Zustand nicht zu bessern. Tod $1 / 210 \mathrm{Uhr}$ Abends.

Nachdem Todewurde wegenderbestehenden Sommerwärme ein den ganzen Kopf umgebender Eisbeatel aufgelegt und bis zar Section liegen gelassen.

Section (Dr. Plotnikow) 12 h. p. m. Chronische ulceröse Pneumonie des linken Oberlappens, Lungenödem. Multiple Farunculose. Linsengrosse Abscesse beider Nieren. Hämorrhagische Herde im Herzfleisch. Pericarditis sero-fibrinosa. Ecchymosen und Hyperämie des Magendarmeanals. Adenome beider Nebennieren.

Nach Eröffrang der Dura mater spinalis zeigt sich eine dem Gebiete der Arachnoides und Pia mater spinalis angehörige, über die bintere Fläche des Rückenmarks in der Ausdehnung rom ersten bis siebenten Dorsalnervenpaar ausgebreitete Gesehwulst von weicher Consistenz und gallertiger, blutig tingirter Beschaffenheit (gefässreiches Myxom), in deren Bereiche die Hinterstränge blass erscheinen and wenig Blutpunkte zeigen.

Schädel dünn; Diploe spärlich. Dura cerebralis etwas dick. Sinus frei. Pia zart und durchscheinend, von der Oberfläche leicht sich lösend. In den Subarachnoidalräumen wenig Flüssigkeit. Consistenz des Gehirns nichts Auffallendes darbietend. Auf den sechs, durch Frontalschnitte entstandenen Gehirnsegmenten erweisen sich die Schnittflächen als mässig spiegelnd, mit wenig Blutpunkten besetzt, graue und weisse Substanz sind überall scharf geschieden; Ventrikel von gewöhnlicher Weite, Ependym zart; überhaupt ist nichts Abnormes auf den Schrittflächen zu sehen und bei der Betastung bieten sie die gewöhnliche fest-weiche Consistenz, wie sie das Gehirn schon als Ganzes dargoboten hatte.

Sämmtliche Gehirnsegmente, Kleinhirn, Oblongata and Rückenmark werden in (häufig gewechselter) Müll er'scher Flüssigkeit gehärtet, nach der Erhärtung nur ein paar Stunden hindurch ausgewässert, dann in starken Spiritus gethan, der so lange gewechselt wird, bis er klar und farblos bleibt.

\section{Mikroskopische Untersuchung.}

Genau symmetrische Stücke werden links und rechts entnommen von:

Gyrus frontalis I., II., III.,

Gyri supraorbitales,

Gyrus rectus,

Gyrus centralis anterior,

Gyrus centralis posterior,

Lobulus paracentralis,

Lobulus parietalis superior,

Gyrus supramarginalis,

Gyrus angularis, 
Gyrus occipitalis I., II., III.,

Cuneus,

Gyrus temporalis I., II., III.,

Gyrus fusiformes,

Gyrus lingualis,

Gyrus fornicatus,

Gyrus hippocampi,

Insel und Claustrum.

Mark des Stirnlappens,

Mark des Scheitellappens,

Mark des Hinterhauptslappens,

Mark des Schläfenlappens,

Nucleus caudatus,

Nucleus lentiformes,

Thalamus opticus.

Ebenso Strïcke rom Corpus callosum und symmetrisohe Stücke vom Kleinhirn. Endlich

Totalquerschnitte von den Vierbügeln nebst Hirnstamm, Brücke, verlängertem Mark, Rückenmark im Halstheil, oberen und unteren Brusttheil, Lendentheil.

\section{Hirnrinde.}

1. Ganglienzellen: Boraxcarminpräparate und Präparate der Weigert'schen Hämatoxylin-, Ferrideyan-, Kalium-Methode mit Alaun-Carmirfärbung und nachfolgender Natronbehandlung.

Die Schichtung der Ganglienzellen verhält sich in diesem Fall an der grossen Masse der untersuchten Windungen (abzüglich der bekannten Variationen) ganz übereinstimmend mit der bekannten Meynert'schen Darstellung und Eintheilung; es sind die grossen Solitärpyramiden am unteren Abschnitt der dritten Schichte gut ausgebildet und die 4. und 5. Zellenschichte sind dentlich differenzirt.

Die Contouren der Zellen sind überall sehr scharf, die Zellen selbst ausgesprochen facettirt. Ihre Ränder sind mit leichten Einkerbungen und schwachen Hervorragungen versehen. Hebt man den Tubus des Mikroskops, so bemerkt man eine grubige Beschaffenheit der Zellenoberfläche. Auch an den Fortsätzen der Zellen zeigt sich vielfach eine solche grubige und warzige Beschaffenheit der Oberfläche. Das Protoplasma der Zellen ist durohaus sehr fein granulirt. Man vermisst die groben Pigmentkörner - otwa vorhandene Fettlörner mussten bei der Härturg in Müller'scher Flüssigkeit und Alkohol verschwinden - welche die normale menschliche und thierische Rindenganglienzelle auszeichnen und in der Nähe des Kernes am dichtesten zu stehen pflegen. Nirgends sieht man eine Andeutung von fibrillärem Bau des Zellenplasma.

Der Kern der Ganglienzellen ist bei Anwendung starker Vergrösserung und engem Diaphragma deutlich nur zu erkennen in den meisten Zellen der 
1., 4. und 5. Sehicht der Hirninde. In der 2. und 3. Schichte, wo grosse Pyramidenzellen den Typus bilden, erseheint er entweder einfach als verwaschener rother Fleck oder man erkennt annähernd die Gestalt desselben, nicht aber seine Begrenzungscontour. Ein gleichmässig aus allerfeinsten stark lichtbrechenden Körnchen bestehendes Protoplasma hüllt ihn wie Staub oder Nebel ein. Von einem Kernkörperchen sieht man in diesen Pyramidenzellen nichts. Aber auch in den Zellen der 1., 4. und 5. Schicht ist ein solches nicht za entdecken. Die Anwendung starker Vergrösserungen (Zeiss-0elImmersion 1/18) ändert nichts an diesem Befunde, welcher in schroffem Gegensatze steht zu demjenigen an den Zellen normaler Hirnrinde vom Menschen und vom Thier, in welchen man Kern und Kernkörperchen bei Bebandlung mit Boraxcarmin so klar untersoheidet. Auch die Weigert'sche Hämatoxylin-Ferridcyankaliummethode verbunden mit Alauncarminfärbung und Entfärbung in Natronlauge bringt an den Zeller aller Schichten der Hirninde nicht das Kernkörperchen zur Darstellung, während sie doch sonst bei den Rindenganglienzellen des Menschen und der Thiere dasselbe als scharf differenzirten schwarzen Punkt anf dem hellen Grunde des Kernes hervortreten macht.

2. Zwischensubstanz (Borax-Carminpräparate). Die Kerne der Zwischensubstanz sind weder auffallend vermehrt, noch vermindert, mit einziger Ausnahme der Windungen des Cuneus der linken und der rechten Hemisphäre. Die Rinde dieser Gyri ist in allen Schichten von einer grossen Menge von Kernen durchsetat.

Die Entfärbung der Zwischensubstanz in salzsaurem Alkohol ist überall vollkommen, nur wiederum in der Rinde der Windungen beider Cunei gelingt sie unvollständig, indem hior ein lebhaftes Blassroth zurüekbleibt. Die Zwischensubstanz zeigt überall jene fibrillär-körnige, poröse Beschaffenheit, welche als charalsteristisch für ihre Textur betrachtet wird.

Ihr Verbältniss zu den Ganglienzellen ist dagegen in sehr auffallender Weise verändert: von den, wie erwähnt, sehr scharfen Zellcontouren ist sie in allen Schnitten aller untersuchten Rindenbezirke mehr oder weniger weit, an manchen Stellen erheblich weit zurückgezogen. Man trifft nur ganz vereinzelt, und zwar lediglich in den zwei oberen Schichten der Hirnrinde, nie in der 4. and 5. Schichte eine Zelle, welcher die Zwischensubstanz knapp anliegt. Es ist also gerade das Gegentheil des Befundes an der Hirnrinde von Gesunden und von Thieren vorhanden, indem in solchen immer nur einzelne Zellen zu sehea sind, welche in einem weiteren Raume der Intercellularsubstanz liegen. Die Hohlränme, welche in unserem Falle die Zellen umgeben, haben im Allgemeinen eine blasige, rundliche Gestalt, welche jedoch noch die Form der. Zelle wiederholt.

Ein morphologisch differenzirter Inhalt dieser pericellulären Räume ist nicht zu erkennen. Bei oberflächlicher Betrachtung sieht man zwar noch im Bereiche der Räume einzelne von schmalen Protoplasmasäumen umgebene Kerne; aber die genauere Betrachtung lehrt, dass dieselben in der abschüssigen Wand des Raumes eingebettet sind, also ausserhalb der Lichtung 
des letzteren liegen. In den Hohlräumen finden sich hier und da (Fig. II. 3) Gruppen von Häufchen feinster Granula, vermuthlich Gerinnungsproducte der die Hohlräume erfüllenden Flüssigkeit.

Vielfach erstreekt sich das erwähnte Missverhältniss zwischen Zelle und umgebendem Hohlranme auch auf die Zellenfortsätze, so dass anch diese von kurzen röhrenförmigen Ausläufern der pericellulären Räume umgeben sind. (Fig. II. 2, 3.)

3. Gefässe (Borax-Carminpräparate). An den kleinen Arterien und Venen sowie an den Capillaren der Corticalis ist keinerlei Veränderung der Wandung zu erkenren. Die perivasculären Räume sind so weit und so eng, wie ich sie in normalen menschlichen und thierischer Hirnrinden bisher immer gefunden habe.

4. Nervenfasern. Da das Gehirn nach der Erbärtung in Müllerscher Flüssigkeit, wenn auch nur einige Stunden gewässert worden war, so konnten von der Weigert'schen Methode entsprechend der vom Autor selbst gemachten Angabe*) keine Erfolge bezüglich der Differenzirung der Nervenfasern erwartet werden. Ich fertigte daher, nach dem Vorgang von Gerlach* ${ }^{*}$, Goldpräparate von den Hirnrindenschnitten an. Die Methode war diejenige von Flechsig*:*) und Freud $\dagger$ ), welche ich in der Weise modificirte, dass das Präparat vor dem Schneiden einige Zeit, jedenfalls nicht unter einer Stunde, in sehr schwachem Spiritus gelegen hatte und auch mit einer Mischung von Spiritus und destillirtem Wasser geschnitten wurde, welche eben gleichmässig die Messerlilinge benetzte; denn starker Spiritus ist dem Gelingen der Goldfärbung ungünstig. Ferner liess ich die Natronlösung nur momentan, die Jodkaliumlösung dagegen mehrere Stunden einwirken und wässerte nach der letzteren die Schnitte wieder ein paar Stunden. Die Schnittdicke betrug 0,010-0,015 $\mathrm{Mm}$., da stärkere Schnitte unklare Bilder der Nervenfasern der Hirnrinde geben.

Diese Goldpräparate nun zeigen eine kaum ausgesprochene, höchstens als leicht violett-grauen Schein za bezeichnende Färbung der Zwischensubstanz, deren Textur unkenntlich ist. Die Ganglienzellen sind nach Einwirkung der Agentien in unserem Falle zu ovalen oder rundlichen, vollkommen farblosén, durchsichtigen Gebilden umgewandelt, in welchen man nur andeutungsweise den Kern als ebenfalls farbloses durchsichtiges, der Zellenform in kleinem Massstabe ähnliches Gebilde, hier und da nur feine Körnchen als Inhalt desselben erkennt.

Sehr scharf dagegen, in den oberen drei Schichten intensiv roth-violett, in den zwei unteren Schichten mehr grau-violett gefärbt, hebt sich das Gewebe des corticalen Nervenfasern in den mit dieser Methode behandelten

*) Fortschritte d. Med. Bd. 2. 1884. No. 6. S. 190.

*) Gerlach a. a. 0 .

*:*) Flechsig, Leitungsbahnen etc. S. 261.

†) Freud, Centralbl. f. d. med. W. 1884 No. 11 und Archiv f. Anat. und physiol. Anat. Abth, 1884. S. 453. 
Schinitten von dem hellen homogenenen Grunde der Zwischensubstanz und den benachbarten ganz unscheinbar gewordenen Ganglienzellen ab.

Das Bild der corticalen Nervenfaserung, wie es der grossen Masse der Grosshirnwindungen eigenthümlich ist, stellt Fig. III. bei schwacher Vergrösserung dar. Das Präparat, welches dieser Zeichnung zu Grande gelegt ist, war dem linken oberen Scheitelläppchen entnommen und genau senkrecht zur Oberfläche geschnitten. Dasselbe lehrt, dass die Nervenfasern in mehrere Kategorien zerfallen: 1. Radiäre von der Markleiste kommende oder nach dieser ziehende Fasern, welche in der gegebenen Abbildung im Längsschnitte sich darstellen und überall senkrecht zur Oberfläche des Gyrus stehen. Sie ordnen sich namentlich in den unteren Schichten der Rinde zu Bündeln, welche in der oberen Schichte gelockert, ja aufgelöst erscheinen. Das Caliber dieser Fasern nimmt von der Oberfläche der Rinde nach dem Mark hin allmälig zu. 2. Circuläre Fasern, welche die radiären rechtwinklig kreuzen und zum Theil die ganze Breite der Schnittfäche durchziehend, öfter einen geschlängelten Verlauf nehmen. Viele dieser Circulärfasern stehen senkrecht zur Schnittfläche und erscheinen dementsprechend als grössere oder kleinere, dunkele, glänzende, auf dem Bilde schwarze Punkte. Auch diese Fasern gewinnen an Caliber in den einzelnen von der Oberfläche nach der Markleiste hin sich folgenden Schichten. 3. Schräge Fasern, welche in verschiedenen Richtungen die anderen kreuzen - am deutlichsten zu sehen in der obersten Schichte (Fig. III. 1). Diese Fasern scheinen hier und da aus radiären Fasern hervorzugehen (vergl. Fig. III. 2).

Die Urtersuchung bei starker Vergrösserung ergiebt, wie schon schwache Vergrösserung annähernd erkennen liess, die schon vor langer Zeit von Köllike $\mathbf{r}^{*}$ ) nachgewiesene Ausbreitung von feinsten Nervenfasern dicht unter der der Gehirnoberfläche, also im äussersten Abschnitte der ersten Schichte. Es sind dies die heute als "tangentiale " bezeichneten Nervenfibrillen. In den unteren zwei Dritteln der ersten (obersten) Schichte der Hirnrinde sieht mar. aber auch sowohl radiäre, als schräge Fasern, welche die, zuerst von Gerla c h beschriebenen Circulärfasern kreuzend, bald im Längsschnitte, bald im Que rschnitte (Punkte in der Abbildung) getroffen sind. In den unteren zwei Dritteln dieser ersten Schichte ist die Zahl der verschiedenen Fasergattungen ungefähr gleich; Unterschiede im Durchmesser derselben treten nicht erheblich hervor. (Fig. IV. 1.)

In der zweiten Schichte (Fig. III. 2) sieht man besonders unter den radiären und cireulären Fasern verbältnissmässig viele Stämmchen von stärkerem Caliber und in Uebereinstimmung damit neben punktförmigen Querschnitten etwa ebenso viel Nervenquersehnitte von grösseren Dimensionen. Eine Bündelbildung ist bei den radiären Fasern eben angedeutet.

Einzelne dieser Radiärfibrillen biegen um den Raum, in welchem eine Zelle liegt, herum und nehmen weiterhin einen eirculären Verlauf. So hat es

") Kölliker a. a. 0.

*) Gerlach a. a. 0 . 
den Anschein, als ob die schrägen Fasern überhaupt, vielleicht auch ein Theil der circulären Fasern aus den radiären hervorgegangen seien.

In der dritten Schichte (Fig. IV. 3) besteht die Nerrenfaserung vorwiegend aus starken Fibrillen und sie bildet hier ein starkes Netz ${ }^{*}$ ), welches Maschenräume - die Räume der Ganglienzellen - umstrickt. Scharf ausgesprochen ist in dieser vorwiegend starke Fibrillen enthaltenden Schichte die Bündelbildung der radiären, angedeutet diejenige der Circulärfasern. Schräge Fasern aller Caliber sieht man hier zablreich ans radiären in den Bündeln enthaltenen Fibrillen hervor und zum Theil in den circulären Faserverlauf eingehen.

Die pierte Schichte (Fjg. IV. 4) enthält ebenfalls vorwiegend starke Fasern von radiärem Verlaufe, welche in lockere Bündel geordnet sind. Oft sieht man nach kurzem Verlauf in schräger Richtung eine solche Faser wieder in den radiären Verlauf eingehen, indem sie sich dem nächsten oder einem entfernteren Radiärbündel zugesellt. Die wenig zablreichen Circulärfasem sind im Allgemeinen von geringem Durchmesser; sie scheinen znm Theil aus radiären Fasern der feinen Gattung hervorgegangen zu sein. Querschnitte von Fibrillen, namentlich starken Calibers sieht man in dieser Schichte in grosser Anzahl.

In der fünften Schichte (Fig. IV. 5) sind die Radiärfasern nur zum Theil in Bündel geordnet. Viele dieser Fibrillen verlaufen als einzelne Stämmchen. Hier nnd da nur verlassen sie die radiäre Richtung, um eine kurze Strecke schräg zu verlaufen und schliesslich wieder in die ursprüngliche Richtung einzulenken. Der Durchmesser dieser Fasern ist im Allgemeinen wieder etwas grösser als in der 4. Schichte. Die circulären Fasern sind hauptsächlich solche von feinem Caliber und sind mit sehr zahlreichen ebenso feinen, schräg verlaufenden Fibrillen durchflochten. Die grösseren Nervenquerdurchschnitte sind in dieser Schichte zahlreich überhaupt und im Vergleich zu der Anzahl der punktförmigen Querschnitte.

In allen Schichten sieht man an den Nervenfasern vielfach die belannten knotigen, oft perlschnnrartig angeordnoten oder spindelförmigen Anschwellungen. Ueber die Differenzirung von Markscheide und Axenoylinder konnte ich bei der angewendeten Goldmethode nicht zu einem ganz sicheren Resultate gelangen und bebalte mir über diese Frage noch weitere Untersuchungen vor. Ich glanbe aber vorläufig annehmen zu müssen, dass es sich bei der Goldmethode um eine Färbung der Axencylinder handelt***). Auch über das Vorkommen von Theilungen der Fibrillen und das Verhältniss der Nervenfasern zu den Ganglienzellen, vermag ioh zur Zeit nichts auszusagen. Prä-

*) Netz ist streng genommen nicht der richtige Ausdruck für die Structur dieser Nervenfaserung, da es sich eben um eine Verwebung der Fibrillen nicht bloss in zwei, sondern in allen drei Dimensionen hazdelt.

**) In der Hirnrinde der Katze fand ich nämlich eine sehr deutliche Differenzirung von Markscheide und Axencylinder bei Goldfärbung: jene war farblos, dieser intensiv violett gefärbt. 
parate; welche ich nach Weigert's Haematoxylin-Ferridcyankalium-Methode anfertigte, lieferten, was ich hier nicht unerwähnt lassen möchte, trotzdem dass das Gehirn dem Wasser ausgeseizt gewesen war, wenigstens in den drei unteren Schichten der Hirnrinde noch gute Bilder der Nervenfasern. Die Netze derselben waren aber weniger dicht als diejenigen, welche die Goldfärbung zur Anschaunng brachte. Mit der ausgezeichneten Methode von Weigert, welche auch die Zellen färbt, war es mir aber auch nicht möglich, Beziehungen derNervenfasern zu den Ganglienzellen der Hirnrinde mil Bestimmtheit zu erkennen.

\section{Hirnmark.}

Borax - Carminpräparate zeigen nur in den unmittelbar der 5. Schichte der Rinde anliegenden Markpartien noch hier und da ähnliohe blasige Hohlräume, wie diejenigen sind, welche die Ganglienzellen der grauen Substanz umgeben. Dieselben umschliessen hier die grösseren, von einem schmalen Protoplasmasaum umrandeten Kerne. In der Tiefe der Marksubstanz aller Hirnlappen sieht man nichts von Hohlräumen dieser Art; das Mark liefert hier den bekannten Befund von Reihen und Nestern kleiner Kerne mit blasser fibrillärer Zwischensubstanz.

Goldpräparate ergeben das Bild, welches Fig. IV. "Mark" wiedergiebt. Man sieht vorwiegend radiär verlaufende Fasern von meist sehr starkem Caliber, untermischt mit wenigen relativ dünnen Fibrillen, daneben schräge, nirgends aber circuläre Fasern. Viele derselben verlaufen leicht geschlängelt und so ist es erklärlich, dass neben rundlichen Querschnitten auch ovale und längliche Abschnitte (schräg durchschnittener) Nervenfasern in dem Bilde auftreten. Knotige und spindelförmige Anschwellungen sieht man anch hier in grösster Menge. Das Marl sieht nicht wesentlich anders aus als auf den Abbildungen von $\operatorname{Exn} \theta \mathrm{r}^{*}$ ) and von Tuczek ${ }^{* * *}$ ), welche Ueberosmiumsäarepräparate wiedergeben; es ist daher wohl die Frage noch weiter zu verfolgen, ob nicht auch die Markscheiden vom Golde gefärbt werden, eine Frage, welche ja anch bezüglich der Nervenfasern der Rinde nicht mit Bestimmtheit entschieden werden konnte.

III. Nucleus caudatus, Nuclens lentiformis, Thalamus, Corpora quadrigemina, Kleinhirn, Pons, Oblongata und alle Abschnitte des Rückenmarks bieten an Borax-Carminpräparater nur die bemerkenswerthe Veränderung, dass überall in der grauen Substanz dieser Abschnitte der Centralorgane die Zellen in etwas erweiterten Hoblräumen liegen, die Kerne der Zellen nur verwaschen sichtbar und Kernkörperchen in derselben gar nicht zu erkennen sind, also einen mit demjenigen der Hirnrindenzellen übereinstimmenden Befund. Am oberen Brusttheil des Rückenmarks findet sich die eben erwähnte Geschwulst, welche sich auch mikroskopisch als gegefässreiches Myxom erweist. Fine Antheilnahme des Rückenmarkes an dem pathologischen Process, der sich in dessen Pia und Arachnoides abgespielt hat,

\footnotetext{
*) Exner a. a. O.

**) Tuczek a. a. 0 .
} 
ist nirgends zu erkennen: die Hinterstränge und der hintere Theil der Seitenstränge zeigen weder Structur- noch Formveränderung.

Im Lendentheil des Rückenmarks findet sich eine Bildungsanomalie der rechten grauer Hintersäule, indem auf eine kurze Strecke die Continuität des grauen Stranges durch weisse Substanz (markhaltige Nervenfasern, die in verschiedenen Riehtungen verlaufen) unterbrochen, daher in eine hintere und vordere Hälfte geschieden ist. Die linke graue Hintersäule ist völlig unverändert.

Der makroskopische Sectionsbefund war, was die wesentlichen Erscheinungen unseres Falles, diejenigen der Dementia anlangt, durchaus negativ. Das Gehirn hätte, wie es sich der Betastung, der Zerlegung in Schnitte und der Betrachtung mit blossem Auge darstellte, ebenso gut einem nicht geisteskranken Individuum angehört haben können.

Die mikroskopische Cntersuchung der Centralorgane des Nervensystems, welche ich, wie ich glaube, mit hinreichender Gründlicbkeit vorgenommen habe, ergab dagegen Resultate, die mit den im Leben beobachteten Störungen der psychischen Thätigkeit im Einklange zu stehen scheinen.

Sebr wichtig ist zunächst der Befund an den Nervenfasern der Rindensubstanz des Grosshirns. Die Netze derselben treten mit einer Schärfe und Vollkommenheit hervor, welche die von der Ueberosmiumsäure hervorgebrachten Bilder weit übertreffen. Ich kann hinzufügen, dass diese mit Gold behandelten Schnitte der Rinde in den beiden oberen Schichten derselben das Gefüge der Nervenfasern deutlicher und gestaltenreicher zur Darstellung bringen, als die Weigert'sche Hämatoxylin-Ferrid-Cyankalium-Methode, welche ich streng nach der Vorschrift des Autors an nicht mit Wasser in Berührung gekommenen Gehirnen (von Thieren und Menschen) anwandte. Es liegt unter solchen Umständen kein Grund zu der Annahme vor, dass die Nervenfasern der Corticalis in unserem Falle erkrankt sind. Einen weiteren Beweis, dass dem so sei, sehe ich in dem Umstande, dass auch die Nervenfasern der Hirnrinde an Thieren (Maulwurf, Katze, Affe) mir genau in derselben Weise mit Gold zu färben gelang. Ich erhielt dabei ähnlich beschaffene Netzwerke; nur sind sie bei diesen Thieren von gröberem und einfacherem Baue wie beim Menschen, was ja bei dem Unterschied zwischen den Leistungen der menschlichen und thie. rischen Hirnrinde nicht weiter auffallend erscheint.

Dem gegenüber gewinnt nun die Thatsache, dass die Ganglienzellen in allen Rindenbezirken, ansgenommen den Cuneus beider Hemisphären und den Lobul. angularis hochgradig verändert sind, 
entscheidende Bedeutung. Während nämlich im Cuneus beiderseits und im linken Lob. angul. nur die Kernkörperchen unsichtbar sind, die Ganglienzellen im Uebrigen aber unverändert erscheinen, ist in den Nervenzellen aller übrigen Theile der Rinde nicht nur das Kernkörperchen unsichtbar, sondern auch der Kern entweder undeutlich oder gar nicht.zu erkennen, während das Protoplasma tiefgreifende Veränderungen in Form einer sehr feinkörnigen stark lichtbrechenden Trübung darbietet. Die Ganglienzellen zeigen zugleich eine Facettirung ihrer Oberfläche und eine knotig-körnige Beschaffenheit der Fortsätze - das was man als Sklerose der Ganglienzellen bezeichnet. Die topographische Figur zeigt die Vertheilung dieser Veränderung über die Hirnrinde in verschiedenen Graden: Schattirung bedeutet Unsichtbarkeit, Schraffirung Undeutlichkeit, weisser Grund Deutlichkeit des Zellkerns.

Als weiterer Befund ergiebt sich ein Missverhältniss zwischen dem Umfang der Rindenganglienzellen und den dieselben umschliessenden Hohlräumen der Zwischensubstanz. Dieses Missverhältniss besteht in allen Schichten der Corticalis. Es werden nur vereinzelte Zellen gefunden, welchen die Wandung der Zwischensubstanz knapp anliegt. Die übrigen trennt ein grosser $Z$ wischenraum von dem umgebenden Gliagewebe. Die topographische Figur bringt die Grade, welche diese Veränderung in den verschiedenen Rindenbezirken zeigt, zur übersichtlichen Anschauung. Die grösseren Kreise auf derselben bedeuten eine erhebliche, diekleinen eine mittelmässige, die Punkte eine geringe Differenz zwischen dem Umfang der Zelle und demjenigen des umgebenden Raumes. Die Rinde beider Cunei und des linken Gyrus angularis bieten den geringsten Grad der Veränderung dar. In den übrigen Rindenbezirken herrscht bald der mittlere, bald der höchste Grad dieser Differenz. An symmetrischen Abschnitten der Rinde beider Hemisphären findet sich nicht überall der gleiche Grad der Veränderung. Nur Gyrus frontalis I. (Zählung von der Fossa Sylvii), centralis post., occip. I., II., III. und Gyrus fornicatus zeigen beiderseits mittelmässig erweiterte pericelluläre Räume, und der höchste Grad der Erweiterung dieser Räume findet sich im Gyrus rectus, supramarginalis, temporalis II., III., lingualis, fusiformis und hippocampi links and rechts.

Es drängt sich bei diesem Befunde zunächst die Frage auf, ob nicht Fäulnissvorgänge oder fehlerhaftie Härtung die Ursachen dieser Erweiterung der pericellulären Räume gewesen seien. Fäulniss konnte wohl kaum angeschuldigt werden, da der Kopf der Leiche vom Momente des Todes bis zur Section unter Lis gehalten und das Gehirn 
nach der Herausnahme und Zerlegung in zahlreiche Stücke sofort in Müller'sche Flüssigkeit gebracht worden war. Weiterhin färbten sich die Ganglienzellen sehr gut mit Carmin, unterschieden sich in dieser Eigenschaft also von den Zellen solcher Gehirne, welche nicht mehr frisch in die Härtungsflüssigkeit gelangt sind. Endlich liessen sich die Nervenfasern aller Rindenschichten durch Goldbehandlung sehr klar zur Anschauung bringen. Gerade in diesem Umstande sehe ich das entscheidende Argument gegen die Annahme, dass Fäulniss die Erweiterung der pericellulären Räume bedingt haben mochte; denn zuerst von allen histologischen Gebilden der Rindensubstanz gehen bei der Fäulniss die Nervenfasern zu Grunde.

Die Annahme, dass ungenaue Härtung die Differenz zwischen Umfang der Zellen und Umfang der umgebenden Räume hervorgebracht habe, ist unberechtigt, weil die Härtungsflüssigkeit wiederholt gewechselt worden war.

Sehen wir vor der Hand von den Zellen und ihrer Beschaffenheit ganz ab und fassen wir nur die dieselbeu umschliessenden Räume in's Auge. Unzweifelhaft sind dieselben im Leben noch weiter gewesen als im mikroskopischen Präparat, da die Härtung immer eine gleichmässige Volumsverminderung des Gehirnes herbeiführt und diese nothwendig zu einer proportionalen Verkleinerung aller im Hirn vorhandenen Hohlräume führen muss.

Es fragt sich nun, wie man sich das Zustandekommen dieser Erweiterung der Zellenräume im Verlaufe der Krankheit zu denken hat? Es wäre möglich, dass ein Transsudations- oder Exsudationsprocess in der Zwischensubstanz des Gehirns stattgefunden nnd zu Flüssigkeitsansammlung zwischen den Zellen und den Wänden der umgebenden Zwischensubstanz geführt hätte. Andererseits wäre möglich, dass jene Räume sich vergrössert hätten durch eine Anschwellung des Zellenleibes.

Eine endgültige Entscheidung dieser Frage ist wobl nur von sehr eingehenden Untersuchungen zu erwarten, welche an frischen und gehärteten Hirnrinden solcher Individuen angestellt werden, die an hoch fieberhaften Krankheiten, bezw. bald nach deren Ablauf gestorben sind. Einstweilen scheint mir eine Wahrnehmung, welche ich in dem beschriebenen Falle machte, dagegen zu sprechen, dass durch Absetzung eines Transsudates oder Exsudates die Erweiterung dieser Räume zu Stande gekommen sei. Es ist dies der sinnenfällige Befund, dass diese Räume vergrösserte Aufrisse der Zellen, welche sie umschliessen, darstellen. Denkt man sich nämlich die Durchmesser dieser Zellen nach allen Richtungen proportional verlängert, so würden 
Zellcontour und Wand des umschliessenden Hohlraumes knapp aneinander liegen.

Die Vermuthung, dass dieses Verhältniss im Leben bestariden habe, ist nicht unberechtigt. Unsere Methoden der Härtung beruhen alle zunächst auf Wasserentziehung. Alkohol löst fernerhin Fette, welche das Zeilenprotoplasma enthält und die chromsauren Salze extrahiren wahrscheinlich gewisse Eiweisskörper. Dementsprechend mochte bei der Härtung dieses Gehirnes eine Volumsreduction der Ganglienzellen stattgefunden haben, welche die Abstände zwischen dem Zellenleib und der umgebenden Wandung hinlänglich erklärt.

Die Verändernngen der Ganglienzellen, welche bei starken Vergrösserungen gefunden wurden, sind geeignet, diese Vermuthung zu stützen: es besteht Trübung des Zellenprotoplasma durch eine sehr feinkörnige, stark lichtbrechende, in Alkohol und ätherischen Oelen unlösliche Substanz, welche zugleich den Zellenkern hier mehr, dort weniger verhüllt und das Kernkörperchen allenthalben durchaus unsichtbar macht. Es handelt sich demnach um albuminöse Trübung des Zellenprotoplasma, um diejenige Veränderung, welche in den Zellen anderer parenchymatösen Organe (Leber, Niere) und den Muskelfasern im Verlaufe und nach Ablauf hochfieberhafter Krankheiten, weiterhin bei chronischen mit Marasmus verbundenen Erkrankungen (Morbus Brightii, Vergiftungen etc.) sehr oft gefunden wird.

Es ist bekannt, dass dieser im Protoplasma der Zellen ablaufende Degenerationsprocess oft eine Schwellung des Zellkörpers mit sich bringt. Untersuchungen an frischen (ungehärteten) Organen haben dies erwiesen; die Bezeichnung „trübe Schwellung“ der parenchymatösen Organe giebt dieser Erkenntniss bündigen Ausdruck. Charakteristisch für den weiteren Verlauf dieses Entartungsprocesses ist fernerhin das massenhafte Auftreten von Fettkörnern im Protoplasma der Zellen. In diesem Stadium der Erkrankung erscheinen die Zellen stark gebläht, sie sind erfüllt mit stark lichtbrechenden Körnern von verschiedenem Kaliber, Kern und Kernkörperchen sind nur undeutlich zu erkennen.

Es liegt auf der Hand, dass die trübe Schwellung und albuminösfettige Degeneration des Zellprotoplasma unter dem Einflusse der gewöhnlich angewendeten Härtungsmethode bestimmte, nicht unerhebliche Veränderungen erleiden muss. Indem die chromsauren Salze gewisse Eiweisskörper lösen, der Alkohol Fette extrahirt, beide Härtungsmittel aber dem Zellprotoplasma Wasser entziehen, ist eine Volumsverminderung der Zelle unausbleiblich. Die Zwischensubstanz, in welche die Nervenzellen der Hirnrinde eingelagert. sind, giebt 
selbstverständlich dieselben Substanzen an die Härtungsflüssigkeiten ab. Offenbar aber hält dieselbe, was die Volumsverminderung bei dem Härtungsvorgange anlangt, nicht immer gleichen Schritt mit den Zellen, weil ihre chemische Constitution eine andere ist. Erreicht nun die von den Härtungsfüssigkeiten hervorgebrachte Schrumpfung: der geschwellten, an löslichen Bestandtheilen reichen Zellen höhere Grade, so müssen nothwendig mehr oder weniger beträchtliche Zwischenräume $z$ wischen den Zellencontouren und den umgebenden Wandungen der Zwischensubstanz entstehen. In diesem Sinne ist nun nach meinem Dafürhalten die Erweiterung der pericellulären Räume in unserem Falle zu erklären und eben in diesem Sinne ist sie auch ein Kunstproduct der Härtung za nennen.

Es handelte sich somit im Leben um eine trübe Schwellung der Ganglienzellen. Diese bedingte eine Erweiterung der die Zellen umschliessenden Hohlräume der Zwischensubstanz. Nach dem Tode unterlagen die Zellen in Folge der Erhärtung einer Schrumpfung, durch welche klaffende Lücken $z$ wischen der Zellenoberfläche und Zwischensubstanz erzeugt wurden. Beiläufig sei hier in Erinnerung gebracht, dass gerade bei Febris recurrens die trübe Schwellung in den übrigen Organen, in der Leber, der Niere, dem Herzfleisch besonders stark ausgesprochen zu sein pflegt.

Das Ergebniss der vorliegenden Beobachtung ist dahin zu verallgemeinern, dass jedenfalls in vielen Fällen die Erweiterung der pericellulären Räume von Härtungsschrumpfung der Ganglienzellen herrührt. Unter zwanzig Gehirnen von Kranken fand ich dieses Missverhältniss zwischen Zellen und umgebenden Räumen bisher dreimal vor. Es hatten in diesen drei Fällen anbaltendes Fieber (Miliartuberculose, käsige Pneumonie) oder schwerer, lange dauernder Narasmus vor dem Tode bestanden. Wichtig ist auch der Umstand, dass von einer grösseren Anzahl von Thiergehirnen, welche ich untersuchte, nur dasjenige eines Hundes diese Veränderung der pericellulären Räume zeigte; dieses Thier war an einem im hiesigen pathologichen Institute experimentell erzeugten Herzklappenfehler zu Grunde gegangen. In allen diesen Gehirnen fand.ich zugleich die Ganglienzellen fein körnig getrübt und deren Kern undentlich, öfter bis zur Unkenntlich keit.

Ist meine Ansicht von dem Zustandekommen der beschriebenen Veränderung der Ganglienzellen in dem Falle von postfebriler Dementia richtig, so wird der Begriff Sklerose der Ganglienzellen zweifelhaft, wo nicht geradezu hinfällig. Unter Sklerose der Nervenzellen 
versteht man bekanntlich nach Meynert's*) Vorgang dieselben Veränderungen, welche ich beschrieben babe und als Schrumpfungszustände parenchymatös getrübter und geschwollener Zellen auffasse: dunkele, unregelmässig scherbenartige, zackig-schollige Beschaffenheit der Zellencontouren, die mit secundären Ecken besetzt sind, höckerige Beschaffenheit der Zellenoberfläche, klumpige, höckerige, opake, glänzend.opalisirende Beschaffenheit des Zellprotoplasma, welches nur selten den Zellkern, hier und da noch das Kernkörperchen durchscheinen lässt; Verdickung der Zellfortsätze; die Zellen selbst entweder aufgebläht, normal gross oder geschrumpft. Manche Forscher, Meynert selbst, Birch-Hirschfeld fügen noch hinzu, dass an den in dieser Weise veränderten Ganglienzellen besonders leicht Sprünge und Risse sich bilden und gerade diese Eigenschaft derselben scheint za der Annahme Veranlassung gegeben zu haben, dass der Aggregatzustand des Protoplasma dieser Zellen verändert sei ( $\sigma x \lambda$ inoós, hart, spröde). Ich muss gestehen, dass ich bei keinem Falle, in welchem ich alle übrigen der sogenannten Sklerose zugeschriebenen Veränderungen der Nervenzellen fand, diese Disposition zur Bildung von Sprüngen und Rissen bemerkt habe.

Aber auch abgesehen davon, dass mir eine besondere Brüchigkeit der sogenannten sklerosirten Zellen nicht aus eigener Erfahrung bekannt geworden ist, scheint mir der bündige Beweis dafür zu mangeln, dass diese behauptete Sprödigkeit und Härte den Zellen schon vor der künstlichen Erhärtung eigenthümlich gewesen sei. Diesen Sachverhalt präsumirt aber doch unbedingt die Bezeichnung Sklerose; denn es bätte doch wirklich keinen Sinn, einen durch Härtung hervorgebrachten Zustand der Zellen mit einem pathologischen Ausdruck zu belegen. Dass Zellen, welche während des Lebens sich im Zustande trüber Schwellung befunden haben, nach der Einwirkung von Müllerscher Flüssigkeit und Alkohol härter sind als normale Ganglienzellen, wissen wir nicht.

Ich lasse daher die ganze Lehre von der Sklerose der Ganglienzellen auf sich beruhen. Nur parenchymatöse Schwellung, welche durch den Härtungsvorgang stark modificirt ist, kann ich als pathologisch-histologischen Begriff für die in Rede stehende Veränderung anerkennen.

Die trübe Schwellung der cortiçalen Ganglienzellen ist in der Histologie der Hirnkrankheiten nicht unbekannt. Schon 1865 be-

*) Meynert, Wiener med. Zeitung 1866 No. 22 und Vierteljahrsschrift f. Psychiatrie Bd. I. 
schrieb Meschede*) dieselbe und stellte sie - es mag unentschieden bleiben mit welchem Rechte - als charakteristische Veränderung der Ganglienzellen bei Dementia paralytica hin. Später wiederum fand Major**) trübe Schwellung der corticalen Ganglienzellen, zumal der zweiten Schichte, bei Dementia senilis und neuerdings hat P. Rosenbach**:) dieselbe in Gehirn und Rückenmark bei Inanition angetroffen.

Allerdings sind zumal von Westphal Zweifel und Einwände gegen die Existenz dieser trüben Schwellung erhoben worden, welche noch nicht beseitigt sind. Ich bin mit weiteren Untersuchungen nach dieser Richtung hin beschäftigt und kann wenigstens so viel mittheilen, dass an frischen Präparaten der Hirnrinde (Gefriermikrotom, kein Zusatz zum Object!) in gewissen Krankheiten sich sehr wohl trübe Schwellung der Ganglienzellen nachweisen lässt.

In dem beschriebenen Falle besteht nun der postmortale Befund ausschliesslich in der Veränderung der corticalen Nervenzellen. Ich glaube, wir dürfen die im Leben beobachteten Erscheinungen von Dementia mit dieser Veränderung in Zusammenhang bringen. Da die Nervenfasern der Hirnrinde nicht die geringste Abnormität erkennen lassen; ist wohl kaum in diese histologischen Elemente der Sitz der Störung zu verlegen. Man müsste denn die Annahme machen wollen, dass die Nervenfasern einer functionellen Störung in Folge der Erkrankung der Ganglienzellen verfallen wären.

Ein isolirter Fall von Geistesstörung gestattet natürlich, auch wenn die mikroskopische Untersuchung der Hirnrinde genau und eingehend vorgenommen worden ist, keine weittragenden Schlüsse in pathologischer Hinsicht. Wichtig erscheint immerhin, dass die Veränderung der Zellen allenthalben in der Hirnrinde vorhanden war. Darin, dass die Intelligenz Gesammtproduct sehr vieler, vielleicht aller Rindenterritorien sei, stimmen ja die Vertreter wie die Gegner der Localisation der Functionen im Grosshirn überein. Dementia ist der Ausfall der Intelligenz; dieser Ausfall ist in unserem Falle demnach wohl das Resultat einer ganz diffusen, auf die Ganglienzellen beschränkten Krankheit gewesen. Dass die pathologische Veränderung in den mittleren Zellenlagen der Corticalsubstanz am stärksten aus-

*) Meschede, Virehow's Archiv Bd. XXXIV. S. 251.

*) Major, West-Riding As. Rep. IV. S. 223; Virchow's Jahresbericht 1874. II. S. 109.

***) P. Rosenbach, Erlenmeyer's Centralblatt 1884. S. 339 und dieses Archiv Bd. XVI. S. $276 \mathrm{f}$. 
gesprochen war, bringt die Erfahrungen von Rindfleis $\left.\operatorname{ch}^{*}\right), \mathrm{Adler}^{* *}$ ) u. A. in Erinnerung, welche bei Zuständen psychomotorischer Aufregung und bei geistiger Schwäche eben auch die Zellen der mittleren Schichten ausschliesslich oder vorzugsweise degenerirt fanden.

Dass die Veränderung der Ganglienzellen in verschiedenen Abschnitten der Hirnrinde verschiedene Grade erkennen lässt, kann nicht auffällig erscheinen, da bei anderen Formen von Dementia dieser Befund ganz gewöhnlich ist. Mit Wernicke $\left.{ }^{* * *}\right)$ können wir die allgemeine Intelligenzschwäche als die $\mathrm{Summe}$ zahlreicher partieller Intelligenzdefecte auffassen. Fortbestehen einzelner Verstandesfähigkeiten in Zuständen von Dementia beruht offenbar darauf, dass gewisse Bezirke der Hirnrinde von dem allgemeinen Krankheitsprocesse wenig oder gar nicht afficirt worden sind. So war in unserem Falle z. B. die Seelenblindheit nur partiell: die Ganglienzellen der Corticalsubstanz im Cuneus beiderseits im linken Lobulus angularis zeigten sich nur sehr wenig verändert, während in den übrigen Windungen beider Hinterhauptlappen und des rechten Lobulus angularis erhebliche Degeneration der Ganglienzellen bestand.

Der Worttaubheit (sensorische Aphasie) und der motorischen Aphasie beziehungsweise Paraphasie entsprachen höhere Grade der Ganglienzellenerkrankungen in der oberen Schläfenwindung und nateren Stirnwindung der linken Hemisphäre.

Die Spuren von Ataxie, bestehend in Ungeschicklichkeit der an sich flinken Bewegungen lassen eine bestimmte Deutung nicht zu, da in der grauen Substanz des Gebirus und des Rückenmarkes die Veränderung der Ganglienzellen allenthalben und ausnahmslos vorhanden war und eben auch hochgradige Abmagerung der Muskulatur bestand. Das Gleiche gilt von dem spontanen Harnabgang bei den Scenen heftigen Widerstandes, wenn man den Kranken festzuhalten suchte.

Ungelöst bleibt fernerhin auch die Frage, welchen Verlauf der Krankheitsprocess genommen haben würde, wenn nicht ulceröse Pneumonie, Marasmus und Furunculose den tödtlichen Ausgang herbeigeführt hätten. Einige Besserung, Wiedergewinn einiger geistiger Fähigkeiten wurde ja bemerkt. Sollte dies der erste Anfang von Wiederaufbau der psychischen Persönlichkeit ( $\mathrm{Sch}$ üle) gewesen sein? Wir wissen es nicht. Herrorzuheben ist aber dennoch abermals, dass

*) Rindfleisch, Pathol. Gewebelehre (I. Aufl.). S. 560 .

**) Adler, Dieses Archiv V. S. 376.

***) Wernicke, Ueber den wissenschaftl. Standpunkt der Psychiatrie. Cassel 1880. S. 14. 
die Nervenfasern der Hirnrinde und des Hirnmarkes keinerlei Veränderung erkennen liessen. Von den Leitungsbabnen her hatte also wohl keine wesentliche Gefahr für den Wiederaufbau der psychischen Persönlichkeit gedroht. In wie weit die nachweisbare Erkrankung: des Ganglienzellenprotoplasma der Ausgleichung fähig zu erachten ist, vermag ich nicht zu entscheiden. Es steht aber fest, dass auch schwere und längere Zeit anhaltende geistige Schwäche nach fieberhaften Krankheiten in manchen Fällen heilbar ist, wie schon Eingangs betont wurde.

Meinem verehrten Collegen R. Thoma, in dessen Institut ich die mikroskopische Untersuchung des Gehirns vornahm, sage ich für seine freundliche Unterstützung bei derselben meinẹn herzlichsten Dank.

Dorpat, den 16./28. März 1886. 
Archio f. Psychiatrie etc. Bd.SITI. Fig.I.
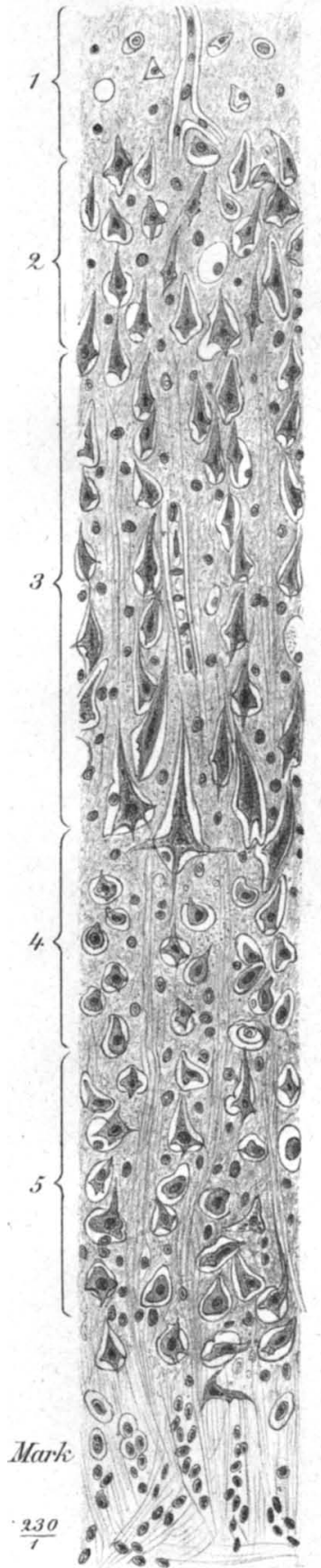

H.Ëmmingheus ad nat, del.
Fig. II. 1.

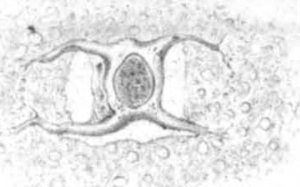

2.
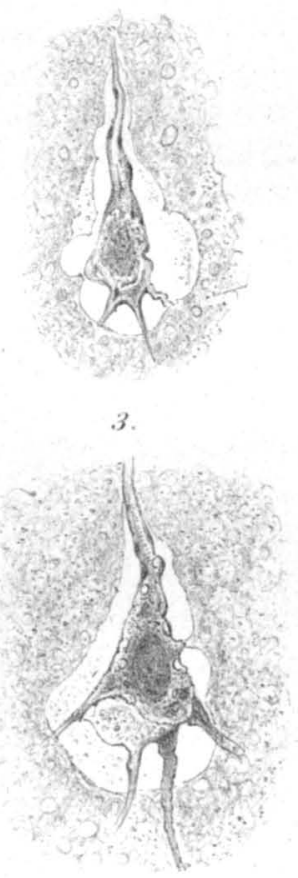

4.

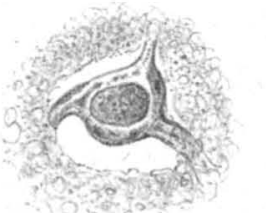

5.

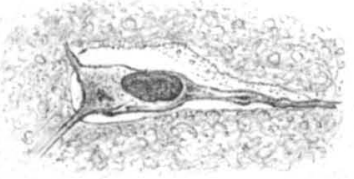

$\frac{810}{1}$
Frig.III.
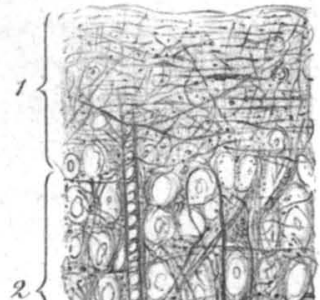

22

wo 0 - 19

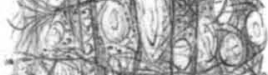

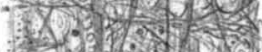

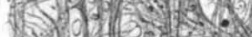

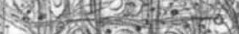

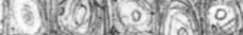

Q 0 (o) $(0)$

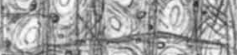

aro $(0)$

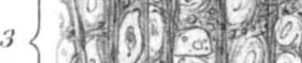

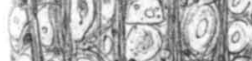

(2) $000 \mathrm{~g}$

(1) $203(2)$

(0) 2010

0. 101020

1. (b)

340 - 15 S

A.

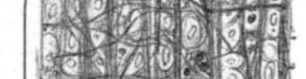

4.

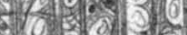

1) 6 (a)

10) 3 o lone

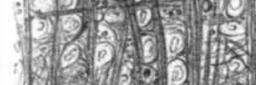

7 . 1460 D
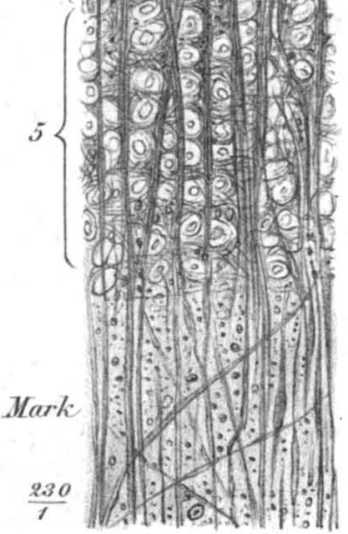

CLaurlith 

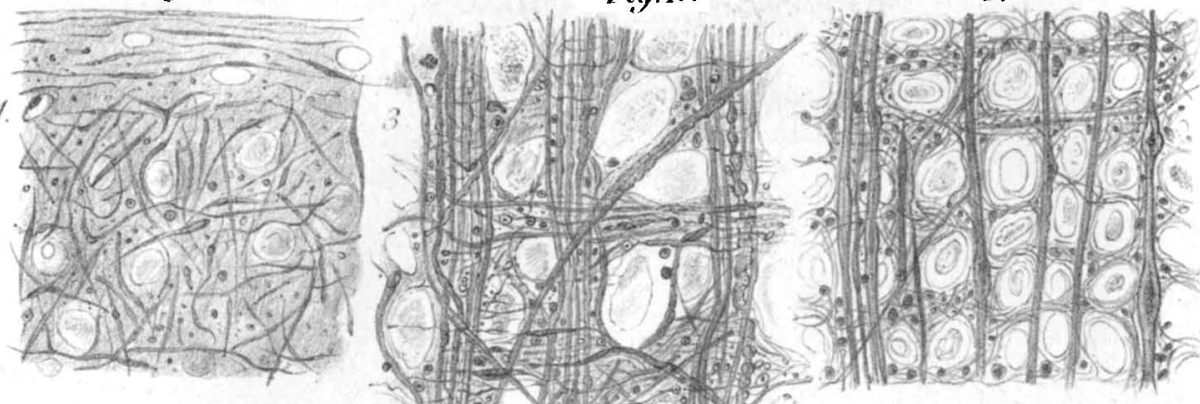

2.
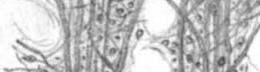

Mfurk:

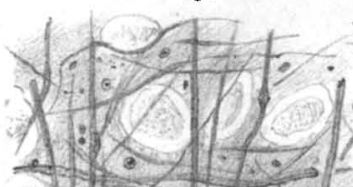
W. $210 \%$

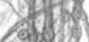

1)

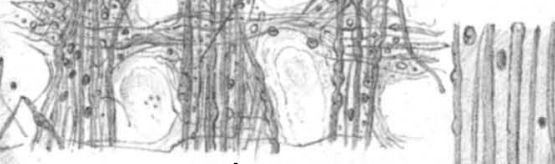

4.

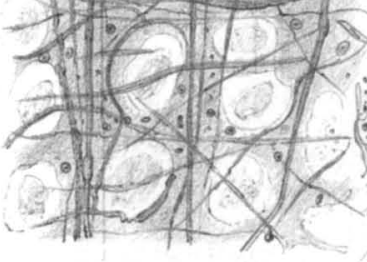

$\frac{74.5}{1}$
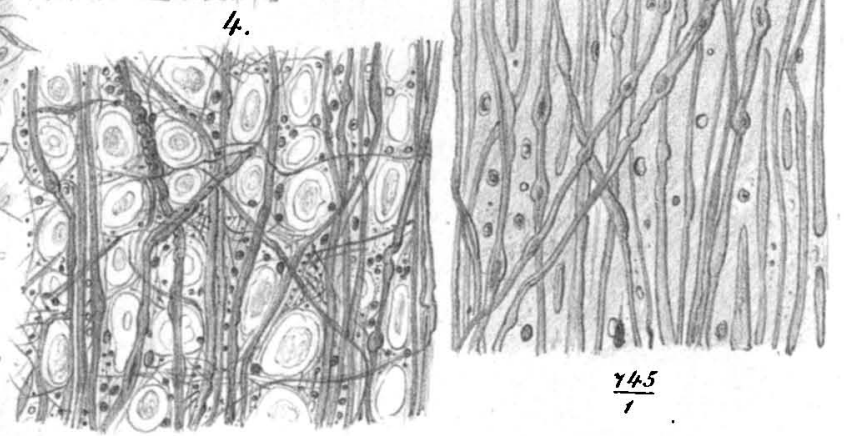

\section{Topograplitische Figur.}
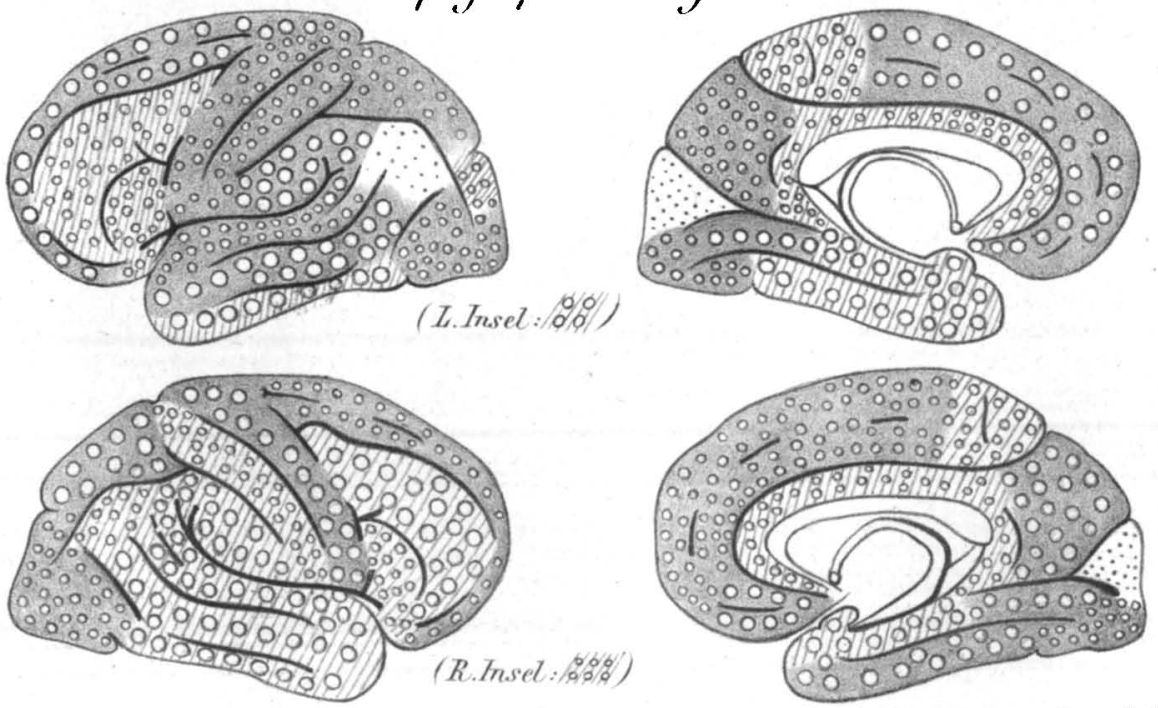

H. Enminghaus ad nat. del.

l. Lauelith. 